\title{
Communities of Chironomidae (Diptera) from four ecological zones delimited by the Mediterranean coastal ecosystems of Morocco (Moroccan Rif). Updated list and faunal data from the last two decades
}

\author{
Kawtar KETTANI,${ }^{*}{ }^{\text {Joel MOUBAYED-BREIL }}{ }^{2}$ \\ ${ }^{1}$ University Abdel Malek Essaadi, Ecology, Systematics and Biodiversity Conservation Team, Tétouan, Morocco; ${ }^{2}$ Freshwater \& Marine \\ biology, 10 rue des Fenouils, F-34070 Montpellier, France \\ *Corresponding author: kettani.ka@gmail.com
}

\begin{abstract}
Based on a large material collected during the last two decades in 43 sites covering a wide range of habitats (fresh and brackish water) we delimited four ecological zones, which extend between sea level and high mountain areas located above $1000 \mathrm{~m}$. The four ecological zones are: Zone 1 (Estuarine zone including pools, ponds, lagoons and wet meadows, altitude 0-10 m); Zone 2 (Potamal, alt. 10-350 m); Zone 3 (Lower basin of streams and wadis (alt. 350-1000 m); Zone 4 (Upper basin of streams, wadis, springs and peat bogs, alt. $>1000 \mathrm{~m}$ ). An updated list of 256 species/taxa belonging to Chironomidae (Diptera) has been established which complements previous data for the chironomid fauna of Morocco. The list includes 72 (28\%) new records for the fauna of Morocco, 21 (8\%) undescribed species and probably 2 new genera (1 Orthocladiinae and 1 Tanytarsini). Spatial distribution of species by subfamilies is highlighted in the four ecological zones where faunal comparative results are: Buchonomyinae (1 species); Tanypodinae (21); Diamesinae (8); Orthocladiinae (143); Chironominae (82, including 40 Chironomini and 42 Tanytarsini). Currently, a total of 410 valid species are reported from Morocco. The low frequency of both listed and undescribed species in Mediterranean coastal ecosystems is linked to the limited faunal knowledge of wetland coastal areas and fragility of lowland habitats, which are regarded as true hotspots.
\end{abstract}

Key words: Moroccan Rif; Mediterranean coastal ecosystems; Diptera Chironomidae; faunal updated data; new records; conservation.

Received: November 2017. Accepted: May 2018.

This paper was presented at the $20^{\text {th }}$ International Symposium on Chironomidae, Trento, Italy, 2-8 July 2017. Session: Ecology and Biomonitoring.

\section{INTRODUCTION}

The present investigation was carried out on 43 sites through the Mediterranean wetland areas of Morocco (Moroccan Rif) and conducted during the last two decades, between 1991 and 2016, where three large biogeograquatic areas are present (Western Rif, Central Rif and Eastern Rif). A preliminary list of the Moroccan Chironomidae focused on the rivers of the Middle Atlas was published by Azzouzi et al., (1987) followed by the additional data of Azzouzi (1992), which dealt with hydrobiological studies from the southern region (High Atlas). Following Azzouzi's contributions, Kettani and others $(1994,1995,1997,2010,2011)$ completed the list of the chironomid fauna of some rivers in the Rif and provided data for the North of Morocco. According to Kettani and Langton (2012) there are about 388 known taxa/species in Morocco. Therefore, the faunal knowledge of this family for Morocco is still limited, patchy and needs to be completed.

The chironomid fauna of Moroccan Mediterranean ecosystems remains little known. All previous records had dealt with a limited geographical area covering a few streams, some large rivers and wadis (Sebou, Tensift, Martil, Laou). Many other wetland areas had remained partly investigated or entirely unexplored. A larger area of the Moroccan Rif has been investigated covering more diverse habitats delimited by the coastal Mediterranean ecosystems. According to the latest updated list of the known Chironomidae from Morocco (Kettani and Langton, 2011, 2012), 388 taxa/species were reported including 338 identified to specific level and 53 to generic level.

In the present paper an updated list of 256 taxa/species (identified by the second author) is provided in Supplementary Tab. S1, which complements previous data for the chironomid fauna of Morocco. The list includes 72 new records (28\%) for Morocco, 21 (8\%) undescribed species and probably 2 new genera ( 1 belonging to Orthocladiinae and 1 to Tanytarsini). Consequently, the list provided by Kettani and Langton is upgraded to 410 taxa/species currently known from this country. 


\section{METHODS}

The investigated area corresponds to the Rifian chain, called the Rif, which includes the most mountainous region of northern Morocco (Fig. 1). The Rif is bordered by the Mediterranean Sea to the north, Algeria to the east and the Atlantic Ocean to the west. The maximum altitude is $2452 \mathrm{~m}$ on the Jbel Tidirrhine. The Rif belongs to the Gibraltar Arc or Alborán Sea geological region, part of the Alpine orogenic belt.

The climate is mainly of Mediterranean type and is characterised by high levels of precipitation and drainage, with an average annual rainfall and soil drainage above $1100 \mathrm{~mm}$. The north of Morocco is considered very rich and diverse in vegetation cover (Valdés et al., 2002) including nearly all of the Moroccan forest species (Médail and Quézel, 1999).

The coast is dominated mainly by coarse sand beaches and pebbles with widespread scree. The watercourse regime is often intermittent or even dry. Some rivers operate only after abundant and continuous rains. Torrential flows are often reported in the area. Most of the investigated temporary streams lie in small catchment basins.

In this diverse Rifain context, a multitude of coastal watersheds extend along the Mediterranean coast: Fnideq at the west to Saïdia, high peaks of the Rif at the east.

\section{Studied sites}

The collection sites (43, Fig. 1) include 37 localities (31 aquatic and 6 terrestrial) which were investigated between 1991 and 2016. The various sites are covered by three broad biogeographic areas: the Western Rif with 14 sites, the Central Rif with 22 sites and the Eastern Rif with 7 sites. The Central Rif, the most diverse part of the Rifian massif, is regarded as the most original entity, with respect to the local floral diversity.

\section{Sampling procedure}

The studied material was mainly collected using standard methods: Surber net for the benthos (larvae and pupae); Brundin drift nets for pharates, pupae, drifting pupal exuviae and drowned adults floating on the surface of the water; Malaise trap supplemented by aerial sweep netting for adults. The examined material consists of $85 \%$ (male adults), 10\% (pupae), 5\% (pharate adults). All specimens were preserved in 70-80\% alcohol and later processed as outlined in Moubayed-Breil (2016).

Four ecological zones, extended along the previous three biogeographic areas (Western Rif, Central Rif and Eastern Rif) comprize the Mediterranean coastal ecosystems of Morocco. Typology and main environmental data for the four ecological zones can be summarized as follows:

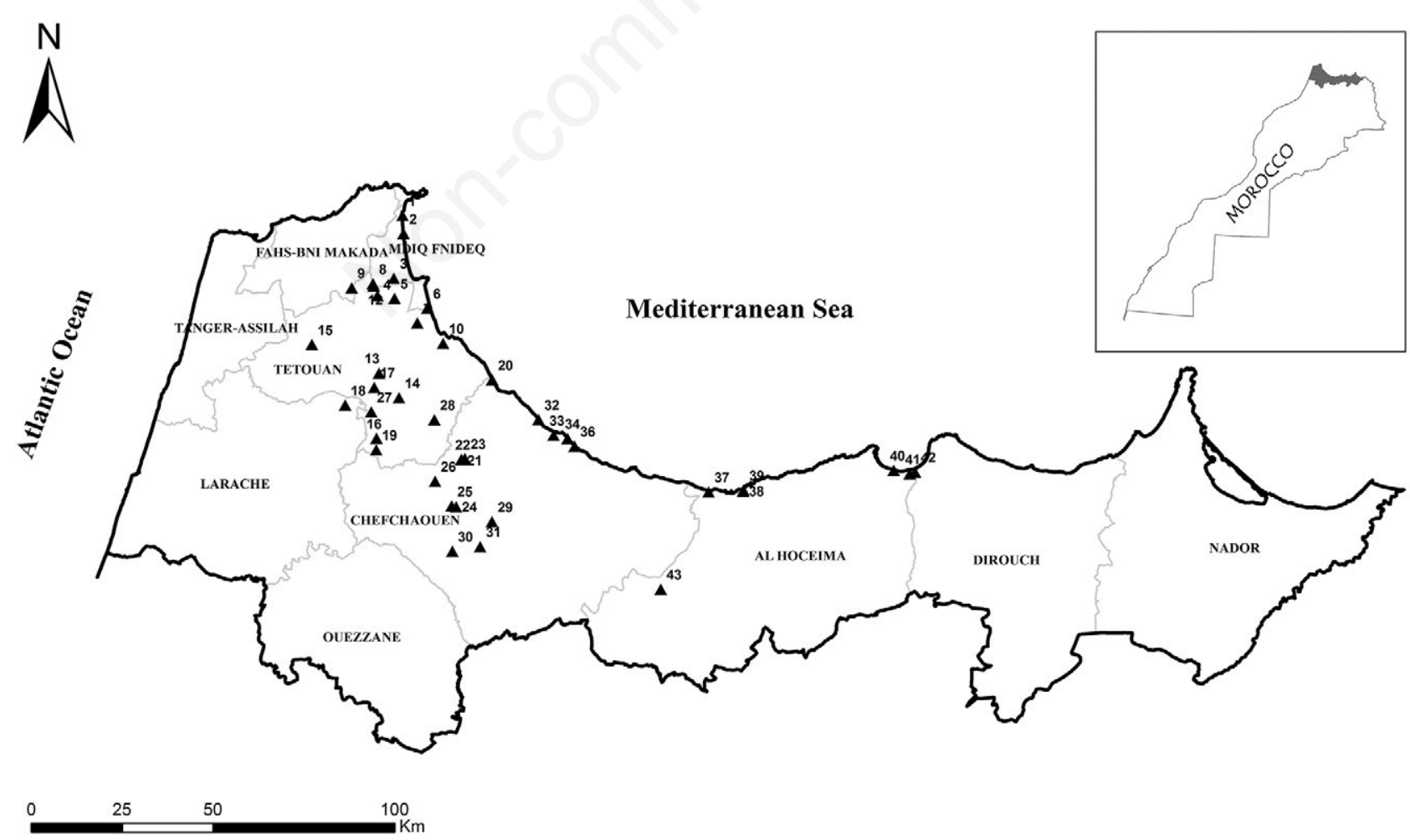

Fig. 1. Major physiographic subregions of the Moroccan Rif with the geographical location of the 43 sampled sites. 
Zone 1 (altitude 0-10 m). Lowest part of potamal (estuarine areas) where habitats consist of rocky and sandy shores with saline pools, ponds and lagoons, and wet meadows dominated by brackish aquatic vegetation (Juncus spp., Typha spp., Salicornia spp., Phragmites spp., Dittrichia viscosa (L.) Greuter, etc.). This zone is markedly affected by human activities, pollution and eco-tourism;

Zone 2 (altitude 10-350 m). Mainly corresponds to the lower basin of large rivers and streams including the potamal section; generally characterized by low slope and relatively deep water. The riparian vegetation is dominated by Nerium oleander L., Tamarix sp., Pistacia lentiscus L., Cistus monspeliensis L., Rubus ulmifolius Schott, and the trees Populus alba L. and Pinus pinaster Aiton;

Zone 3 (altitude 350-1000 m). Rhithral section where there are shady stretches of streams and wadis including bryocolous and hygropetric habitats, small to large waterfalls and riffles with sandy to gravely substrata. Major riparian forest, aquatic and subaquatic vegetation mainly belong to riparian species including: Nerium oleander, Tamarix africana Poir., Pistacia lentiscus, Cistus albidus L., Tetraclinis articulata (Vetel) Mast., Erica arborea L., Quercus suber L., Alnus glutinosa (L.) Gaertn. and Pinus pinaster;

Zone 4 (altitude $>\mathbf{1 0 0 0} \mathbf{~ m}$ ). Epirhithral section of streams and wadi, high mountain springs and peat bogs extending above $1000 \mathrm{~m}$ in altitude. Encountered riparian trees include: Abies marocana Trab. (fir forest), Cedrus atlantica (Endl.) Carrière (cedar forest), Quercus canariensis Willd. (Zénaie) and Quercus ilex L.

\section{RESULTS AND DISCUSSION}

\section{Faunal approach}

An updated list of 256 species is here reported from the Moroccan Rif region, including 71 genera in 6 subfamilies (Tab. 1): Buchonomyinae (1 species), Tanypodinae (21 species), Diamesinae (8), Prodiamesinae (1), Orthocladiinae (143) and Chironominae (82). Of the 256 listed species, there are $72(28 \%)$ new records for the fauna of Morocco, including 21 (8\%) undescribed species which seem to be new for science and 2 new genera, increasing the total number of known valid species to 410 for this country.

Of the 72 new records 54 species belong to Orthocladiinae $(75 \%), 15(21 \%)$ to Chironominae, 2 to Tanypodinae and only 1 to the Diamesinae. Among the total of 71 genera, 7 are reported for the first time from Morocco: Acricotopus, Camptocladius, Hydrobaenus, Smittia, Thienemannia, Cladopelma and Stenochironomus. The highest number of species for Morocco now belongs to the Orthocladiinae (30 genera, 143 species) followed by the Chironominae $(23,82)$. The most diverse genera are: Cricotopus (22 species) followed by Eukiefferiella (15). A lower number of species (less than 10) belongs to the following genera: Bryophaenocladius, Limnophyes, Orthocladius, Tanytarsus, Rheocricotopus, Micropsectra, Rheotanytarsus, Chironomus, Polypedilum, Pseudosmittia, Smittia. Three orthoclad genera with potential biogeographic value (Heleniella, Krenosmittia and Thienemannia) have still not been encountered in the investigated areas.

\section{Ecological and biogeographic approach}

The distribution pattern of specific richness along the four ecological zones revealed the presence of four distinct communities (Tab. S1). The highest diversity is recorded in the rhithral of middle basins of streams and rivers (zone 3 ) with 188 species, followed by zone 2 (152). Zones 1 and 4 are represented by fewer species: respectively 80 and 88 . The highest diversity reported in the metarhithral of streams (zone 3: 188 species, 73\%) and potamal section of large

Tab. 1. Distribution by subfamilies of genera/species (number and percentage) of Chironomidae in the four ecological zones of the Moroccan Rif (Mediterranean coast, N-Morocco). Typology of the four ecological zones: 1, estuarine zone including pools and wet meadows (altitude 0-10 m); 2, Potamal (alt. 10-350 m); 3, lower basin of streams and wadi (alt. 350-1000 m); 4, upper basin of streams, springs, peat bogs (alt. $>1000 \mathrm{~m}$ ).

\begin{tabular}{|c|c|c|c|c|}
\hline Chironomidae (subfamilies) / Ecological zones & Zone 1 & Zone 2 & Zone 3 & Zone 4 \\
\hline Buchonomyinae: $1 / 1$ & - & 1 & 1 & - \\
\hline Tanypodinae: $12 / 21$ & 6 & 17 & 14 & 4 \\
\hline Diamesinae: $4 / 8$ & - & 3 & 6 & 3 \\
\hline Prodiamesinae: $1 / 1$ & 1 & 1 & 1 & - \\
\hline Orthocladiinae: $30 / 143$ & 30 & 63 & 124 & 73 \\
\hline Chironominae: $23 / 82$ & 43 & 67 & 42 & 8 \\
\hline Chironominae-Chironomini: $15 / 40$ & 28 & 37 & 16 & - \\
\hline Chironominae-Tanytarsini: $8 / 42$ & 15 & 30 & 26 & 8 \\
\hline Total genera $=71 /$ Total species $=256$ & 80 & 152 & 188 & 88 \\
\hline$\%$ & 31 & 59 & 73 & 34 \\
\hline
\end{tabular}


rivers (zone 2: 152, 59\%), reveals an important ecological potential for the occurrence of a great number of species. In particular, the high specific richness of zone 4 is certainly related to the heterogeneity of habitats, which consists mainly of short sections of rhithral with small riffles and waterfalls. Fourteen taxa were recorded exclusively from this section: Diamesa hamaticornis Kieffer, D. insignipes Kieffer, Bryophaenocladius sp.3, Cricotopus (C.) pulchripes Verrall, C. (Paratrichocladius) sp.2, Hydrosmittia ruttneri (Strenzke \& Thienemann), Orthocladius (O.) sp.1, Parametriocnemus valescurensis Moubayed \& Langton, Paraphaenocladius exagitans (Johannsen) ssp.1, Psectrocladius (Allopsectrocladius) platypus (Edwards), P. (Psectrocladius) octomoculatus Wülker, Demicryptochironomus (Irmakia) neglectus Reiss, Rheotanytarsus distinctissimus (Brundin), and R. reissi Lehmann.

The lowest number of species (80) is reported from zone 1, where the Chironominae is represented by 43 species. This decrease in richness is certainly due to human activities and disturbances that include pollution and variation in flow observed near the coast (most estuaries are dry over long periods of the year). The estuarine zone and coast constitute a vulnerable habitat which suffers nowadays greatly from both natural (climate change) and anthropogenic effects. Five species occurring in zone 1 are exclusively reported from this area: Hydrobaenus conformis (Holmgren), Chironomus (Baeotendipes) noctivagus (Kieffer), Chironomus aprilinus Meigen, C. salinarius Kieffer and Tanytarsus formosanus Kieffer. In addition 16 other new records for Morocco have been recorded from the coast: Acricotopus lucens (Zetterstedt), Bryophaenocladius tuberculatus (Edwards), Camptocladius stercorarius (DeGeer), Cricotopus (C.) caducus Hirvenoja, C. (C.) ephippium (Zetterstedt), Limnophyes habilis (Walker), L. madeirae Sæther, L. natalensis (Kieffer), Nanocladius dichromus (Kieffer), Smittia pratorum Goetghebuer, Cladopelma virescens (Meigen), Cryptochironomus supplicans (Meigen), Stenochironomus gibbus Fabricius, Stictochironomus rosenschoeldi (Zetterstedt), Tanytarsus ejuncidus (Walker), and T. mendax Kieffer.

The poor specific richness of zone 4 (only 88 species) compared to that of the other zones, is closely related to limited investigations and the low number of explored localities (only 6 sites). Nevertheless, it is important to highlight that in this community, 48 taxa $(19 \%)$ are considered to be new records for Morocco, including 14 undescribed taxa with 2 new genera (1 Orthocladiinae and 1 Tanytarsini). In addition, Zavrelimyia barbatipes (Kieffer), Z. berberi Fittkau, Corynoneura celtica Edwards and Lithotanytarsus dadesi Reiss are exclusively reported from this mountainous area.

The presence of 21 new undescribed species and 2 new genera in high mountain areas (zone 4) highlights the importance of cold and stenothermic habitats, which are considered to be hotspots of diversity and endemism. Therefore, this mountain range of the Moroccan Rif deserves greater consideration and preservation, where more hydrobiological plans are still necessary to be implemented in the years to come.

\section{ACKNOWLEDGMENTS}

We wish to thank our colleagues Dr P.S. Cranston, Dr N. Prat and Dr P. Ashe for their constructive suggestions and corrections, which markedly improved the manuscript.

\section{REFERENCES}

Azzouzi A, Laville H, 1987. [Premier inventaire faunistique des Chironomidés (Diptera, Chironomidae) du Maroc].[Article in French]. Ann. Limnol.-Int. J. Limn. 23:217-224.

Azzouzi A, Laville H, Reiss F, 1992. [Nouvelles récoltes de Chironomidés (Diptera) du Maroc].[Article in French]. Ann. Limnol.-Int. J. Lim. 28:225-232.

Benabid A, 2000. [Flore et écosystèmes du Maroc. Évaluation et préservation de la biodiversité].[Book in French]. Ibis Press, Paris: 357 pp.

Kettani K, Vilchez A, Calle D, El Ouazzani T, 1994. [Les Chironomidés (Diptera) du bassin de l'Oued Laou (Versant méditerranéen du Rif, Maroc)].[Article in French]. Ann. Limnol.-Int. J. Lim. 30:25-32.

Kettani K, Vilchez A, Calle D, El Ouazzani T, 1995. [Nouvelles récoltes de Chironomidés (Diptera) du Maroc: Les Chironomidés de 1'Oued Martil (Rif)].[Article in French]. Ann. Limnol.-Int. J. Lim. 31:253-261.

Kettani K, Calle D, El Ouazzani T, 1997. [Nuevas especies de Quironomidos (Insecta - Diptera) en el alto Laou (Rif, norte de Marruecos)].[Article in Spanish]. Zool. Baetica 8: 181-189.

Kettani K, Langton P, 2011. New data on the Chironomidae (Diptera) of the Rif (Northern Morocco). Pol. J. Entomol. 80:583-595.

Kettani K, Langton P, 2012. [Les Chironomidae du Maroc (Diptera, Nematocera)].[Article in French]. Bull. Soc. Entomol. Fr. 117:411-424.

Médail F, Quézel P, 1999. Biodiversity hotspots in the Mediterranean Basin: setting global conservation priorities. Conserv. Biol. 13:1510-1513.

Moubayed-Breil J, 2016. On the genus Cricotopus v. d. Wulp, 1874 (tremulus-group) from continental France and Corsica with description of C. mantetanus sp. n. and C. royanus sp. n. [Diptera, Chironomidae, Orthocladiinae]. Ephemera 17:71-104.

Valdés B, Rejdali M, Achhal el Kadmiri A, Jury JL, Montserrat JM, 2002. [Catalogue des plantes vasculaires du nord du Maroc, incluant des clés d'identification].[Book in Spanish]. Consejo superior de investigacione scientíficas: $1007 \mathrm{pp}$. 